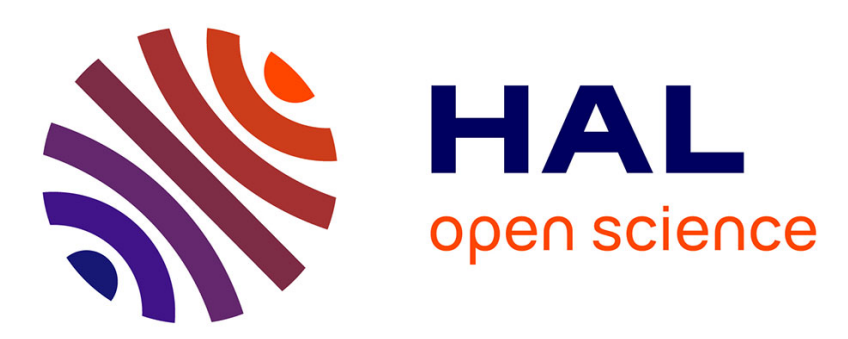

\title{
Short carbon fiber-aluminium matrix composite material prepared by extrusion of powder mixtures
}

\author{
E. Simancik, G. Jangg, H. Degischer
}

\section{To cite this version:}

E. Simancik, G. Jangg, H. Degischer. Short carbon fiber-aluminium matrix composite material prepared by extrusion of powder mixtures. Journal de Physique IV Proceedings, 1993, 03 (C7), pp.C71775-C7-1780. 10.1051/jp4:19937281 . jpa-00251923

\section{HAL Id: jpa-00251923 https://hal.science/jpa-00251923}

Submitted on 1 Jan 1993

HAL is a multi-disciplinary open access archive for the deposit and dissemination of scientific research documents, whether they are published or not. The documents may come from teaching and research institutions in France or abroad, or from public or private research centers.
L'archive ouverte pluridisciplinaire HAL, est destinée au dépôt et à la diffusion de documents scientifiques de niveau recherche, publiés ou non, émanant des établissements d'enseignement et de recherche français ou étrangers, des laboratoires publics ou privés. 


\title{
Short carbon fiber-aluminium matrix composite material prepared by extrusion of powder mixtures
}

\author{
F. SIMANCIK, G. JANGG and H.P. DEGISCHER ${ }^{*}$ \\ Institute for Chemical Technology of Inorganic Materials, TU Vienna, Getreidemarkt 9-161, 1060 Vienna, \\ Austria \\ ${ }^{*}$ AMAG-Forschungs- und Entwicklungsges.m.b.H., 5282 Braunau-Ranshofen, Austria
}

\begin{abstract}
Unidirectional short carbon fiber/aluminum matrix composites have been prepared by hot extrusion of fiber/powder mixtures. Effects of processing parameters on the fiber length and the interfacial reaction between fibers and aluminium have been studied. Composites with different fiber volume fraction (up to $15 \mathrm{vol}$. \%) were tested on their longitudinal stiffness and tensile strength at room as well as elevated temperatures to investigate the strengthening effect caused by addition of fibers into the matrix material. An experiment of annealing of the composites was done to study the influence of annealing time and temperature on the interfacial bonding strength and on the amount of reaction product $\left(\mathrm{Al}_{4} \mathrm{C}_{3}\right)$ at the interface.
\end{abstract}

\section{INTRODUCTION}

Carbon fibers (CF) possess highest specific stiffness compared with other ceramic reinforcements. In addition, they are commercially available at relative low cost and they are not health hazardous. These properties makes them attractive as a reinforcement for light metals such as aluminum and its alloys. However, interfacial reaction at higher temperatures requires the protection of the fibers, especially when the composite is prepared using liquid matrix [1], which makes the fabrication of composites difficult and expensive. In order to develop a cost effective manufacturing technique, the ideal solution would be the elimination of the need for a fiber coating via minimization of the interfacial reaction by reducing the contact time between fibers and metal at extremely high temperature. This demand can be accomplished by extrusion of fiber/powder mixtures because it involves a solid state process and allows very high compacting rates. Moreover, the extrusion provides a method for direct production of various long profiles in which the longitudinal properties are dominant. The reinforcing fibers can be easily aligned in this direction. However, the major drawback of powder metallurgical techniques is extreme fiber damage during processing resulting in significant reduction of reinforcing efficiency $[2,3]$. The aim of this study is to investigate the structural and mechanical properties of short CF/Al-matrix composites prepared by powder metallurgical techniques which have been optimized to minimize the fiber shortening and the interfacial reaction between the constituents.

\section{EXPERIMENTAL}

Commercially pure Al (ECKA AS011/S) and age hardenable 6061-aluminum alloy powders (mean size $\sim 32 \mu \mathrm{m}$ ) were employed as a matrix material. Powder and short carbon fibers Courtaulds Grafil HMS (density $\sim 1.87 \mathrm{~g} / \mathrm{cm}^{3}$, ultimate tensile stress $\sim 3 \mathrm{GPa}$, Young's modulus $\sim 390 \mathrm{GPa}$, diameter $\sim 6.5 \mu \mathrm{m}$, mean length $\sim 1 \mathrm{~mm}$ ) were wet mixed, then unidirectionally oriented and hot pressed into billets perpendicularly to the fiber orientation, in Ar-atmosphere. The billets were hot extruded at a ram speed of $3 \mathrm{~cm} / \mathrm{s}$ using a round die (extrusion ratio $1: 16$, die entrance angle $90^{\circ}$ ). Some of the aligned fiber-powder mixtures were 
canned into $\mathrm{Al}$-cans and hot extruded without pre-densification as loose mixtures. The extruded 6061matrix composites were heat treated under $\mathrm{T} 6$ conditions (solutioning at $530^{\circ} \mathrm{C}$, water quenching and annealing at $177^{\circ} \mathrm{C}$ for 8 hours). The fiber length in the extruded composite was determined from the micrograph of the filter cake after first dissolving the matrix in $\mathrm{HCl}$. Approximately 200-300 fibers were measured for each sample. Tensile strength measurement was performed on an Instron ${ }^{\mathrm{TM}}$ testing machine at a cross-head speed of $0.1 \mathrm{~cm} \mathrm{~min}^{-1}$. The shoulder-type specimen was held at the test temperature with the accuracy of $\pm 2 \mathrm{~K}$ for $10 \mathrm{~min}$. In order to stabilize the matrix structure at the testing temperature, each specimen was annealed for 24 hours in an external furnace at this temperature, then furnace cooled and immediately prior to testing again reheated. An electronical extensometer with a gauge length of $25 \mathrm{~mm}$ was connected to the specimen during tensile testing at room temperature. Young's modulus was determined from the linear part of the stress-strain diagram. A linear curve was obtained by reversing the cross-head motion at the strain of $0.1 \%$. The amount of aluminum carbide was computed from the $\mathrm{H}_{2}: \mathrm{CH}_{4}$ ratio determined by gas chromatography after dissolving the composite in $\mathrm{NaOH}$.

\section{RESULTS AND DISCUSSION}

\section{Structure of the extruded composite}

Fibers in extruded bars are relatively uniformly distributed and well aligned unidirectionally into the extrusion direction (Fig. 1). Satisfactory fiber distribution has been obtained for fiber volume fractions up to 0.15 . Higher fiber fractions resulted in improper embedding of the fibers in the matrix.

Fiber length. Fiber shortening during composite preparation is the major shortcoming of the applied fabrication method. Fibers long initially about $1 \mathrm{~mm}$ (mean aspect ratio $\sim 150-160$ ) have been fragmented into short lengths in following processing sequence:

i) almost no shortening during wet blending, orienting and drying (1/d 140-150)

ii) moderate shortening during hot pressing, depending on pressing temperature and pressure (1/d 80-120)

iii) extreme shortening during hot extrusion (1/d 5-50)

Detrimental fiber damage occurs during onset of extrusion due to a significant level of shear stresses arising in the extrusion die [4]. With increasing temperature the matrix shear stress decreases resulting thus in less fiber breakage (Fig. 2). More intensive fiber damage during extrusion of hot pressed billets, compared to those using loose mixtures, can be attributed to the embrittlement of the fiber-matrix interface in the billets caused by chemical reaction between $\mathrm{Al}$ and $\mathrm{C}$-fibers during hot pressing and heating before extrusion. Composites with a fiber aspect ratio up to 50 (Fig. 3) can be prepared using extrusion temperatures in the semi-solid range (6061-matrix).
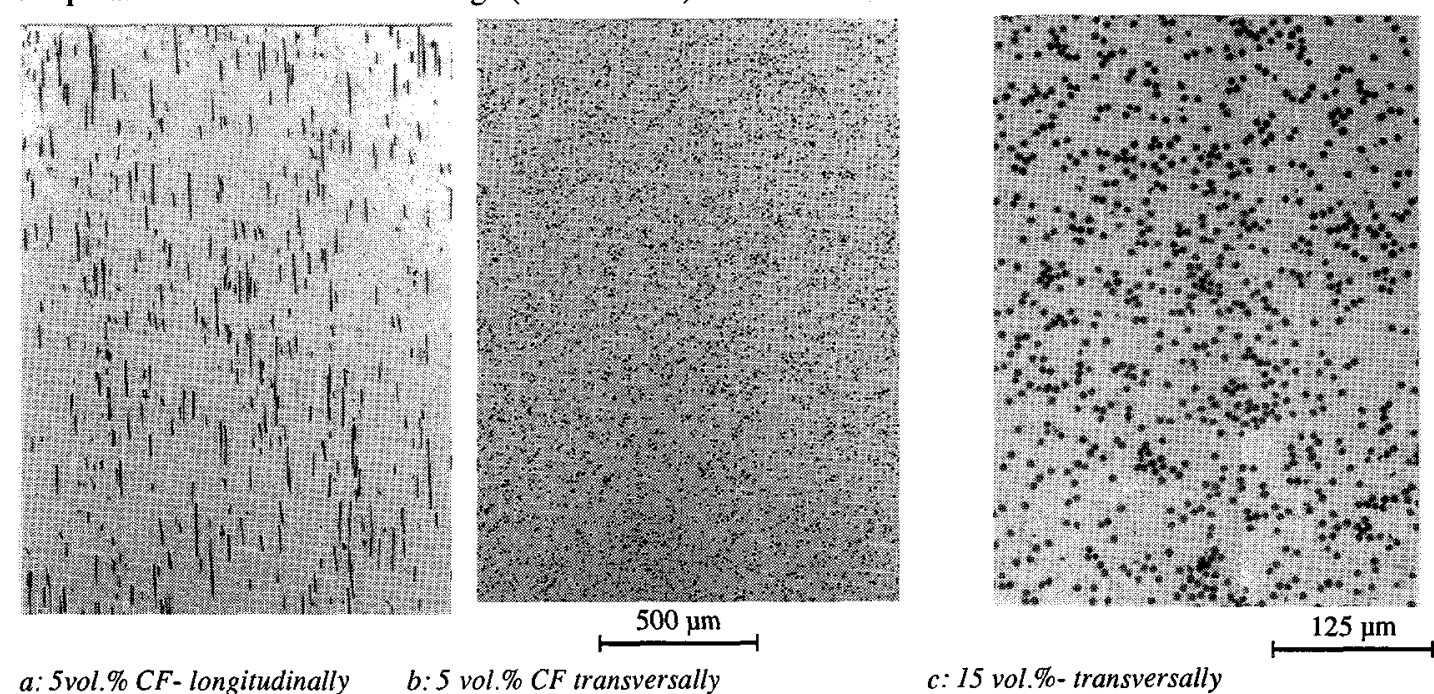

a: 5 vol.\% CF- longitudinally

$b: 5$ vol.\% CF transversally

c: 15 vol.\%- transversally

Fig.1 Cross sections of extruded Al-matrix composites 


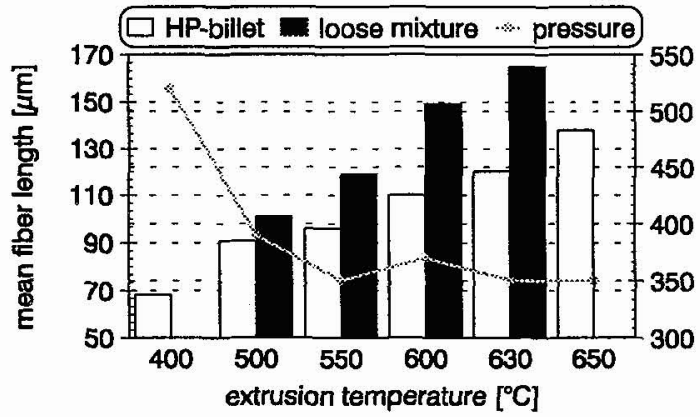

Fig. 2 Mean fiber length and extrusion breaktrough pressure at different extrusion temperatures

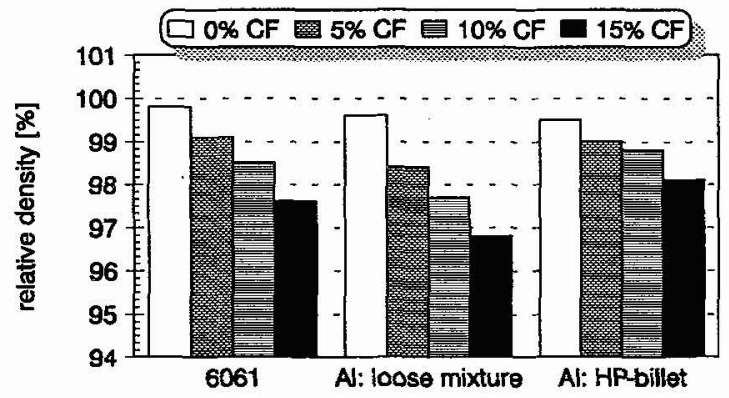

Fig. 4 Relative density of extruded composites

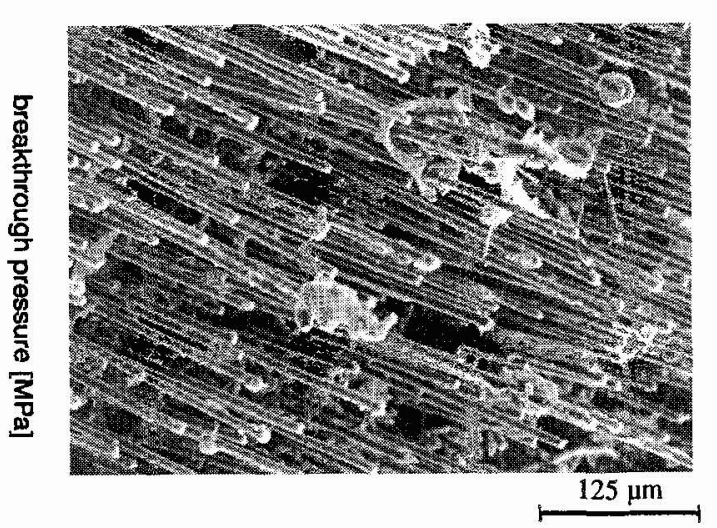

Fig.3 SEM of extruded 6061-matrix/ 10 vol.\% CF composite (deep etched)

Relative density of the composites (ratio of the experimentally achieved density to the theoretical one) decreases with increasing fiber volume fraction (Fig. 4). The effect of the matrix can also be noticed. Partially liquid 6061-matrix possesses more fluidity than solid Al-matrix and allows thus better embedding of fibers which results in higher final density. Composites extruded from hot pressed billets exhibit slightly higher densities than those extruded from loose mixtures. This can be explained as follows: The true densification of the composite is completed after elimination of free interparticle (fiber) surfaces. This process is driven by diffusion and is to a certain degree realized during hot pressing. Assuming that the diffusion controlled increase of density during extrusion is the same for both hot pressed and loose mixture billets, the final density of composites extruded from hot pressed billets should be higher.

\section{Interfacial reaction.}

Aluminum carbide amounts determined in composites prepared by different methods are listed in Table 1. Almost no interfacial reaction has been observed in composites extruded from loose mixtures. The chemical reaction between fiber and matrix during heating of loose mixture has been precluded by the presence of inactive alumina on the powder surface. Suitable conditions for interfacial reaction are created only after application of sufficient deformation on mixture, e.g. during upsetting stage of extrusion. As the extrusion is relatively fast it cannot provide sufficient time for diffusion and significant carbide growth. This leads to an assumption that the interfacial reaction in composites extruded from hot pressed billets takes place predominantly during hot pressing and heating of the billets to extrusion temperature. Higher carbide quantities in 6061 matrix composites were caused by the presence of liquid phase in this matrix material during extrusion. Liquid phase dissolves a certain amount of carbon and provides better conditions for diffusion and hence more intensive interfacial reaction than the solid phase. 


\section{Mechanical properties}

Young's modulus of composites determined parallel to the fiber alignment is shown in Fig. 5. As expected it increases with increasing fiber volume fraction. Despite shorter fiber lengths the longitudinal stiffness of composites extruded from hot pressed billets is higher than that of composites extruded from loose mixtures. This effect can be attributed to the improved fiber-matrix bonding due to the higher degree of interfacial reaction in these composites. The experimentally measured moduli attain almost the theoretical values computed according to the "Halpin-Tsai"

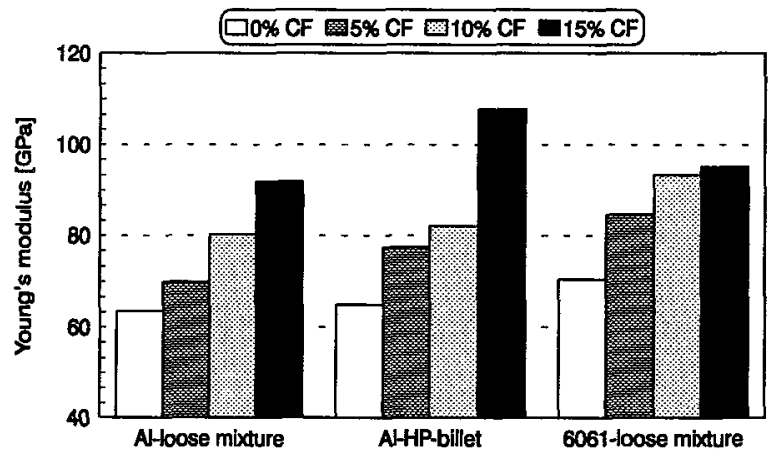

Fig.5 Longitudinal Young's modulus of extruded composites for different fiber volume fraction equation [5] considering also the effect of residual porosity.

Ultimate tensile stress at room and elevated temperature of composites extruded from loose mixtures is summarized in Table 2. The strength of Al-matrix composites increases with increasing fiber volume fraction $V_{f}$, although the reinforcing efficiency is low. Insufficient fiber strengthening is due to the weak bonding between fibers and matrix. According to previous calculations [6] the average interfacial shear stress does not exceed the value of $25 \mathrm{MPa}$. Since this value is considerably lower than the matrix shear yield stress $\tau_{\mathrm{y}}$ the load transferred from the matrix onto the fiber remains almost unchanged up to $300^{\circ} \mathrm{C}$. It results in increasing efficiency of reinforcement with increasing temperature, because the matrix strength decreases. At higher temperatures $\tau_{y}$ significantly decreases, becomes smaller than the interfacial bonding strength and begins to control the load transfer. This leads to the slight reduction of reinforcing efficiency. Moreover, the interfacial reaction between fiber and matrix takes place at temperatures above $400^{\circ} \mathrm{C}$, resulting in substantial reduction of the fiber strength. This has been confirmed by measurement of lengths of fibers extracted from $\mathrm{Al}-$ matrix/10 vol.\% CF composite after tensile testing. Fiber lengths in composites tested at temperatures up to $400^{\circ} \mathrm{C}$ were about the same as those measured before testing (mean lengths $\sim 130-150 \mu \mathrm{m}$ ), while the fibers in composites tested at $500^{\circ} \mathrm{C}$ were notably fragmented (mean length $\sim 71$ $\mu \mathrm{m})$. Weak interfacial bonding leads to high critical fiber length and thus in high minimal fiber volume fraction $V_{\min }$ (see [7]). As can be estimated in Fig. 6, $V_{\min }$ for Al-matrix composites belongs to the range of $(0.1-0.15)$ at $20^{\circ} \mathrm{C},(0.05-0.1)$ at $100^{\circ} \mathrm{C}$ and $(0-0.05)$ at $>100^{\circ} \mathrm{C}$. Slight strengthening observed at the composite in which $V_{f}<V_{\text {min }}$, can be attributed to the changes in matrix structure [8].

Table 2 Ultimate tensile stress [MPa] of extruded short carbon fiber composites at different testing temperatures (average of at least 3 measurements)

\begin{tabular}{|c||c|c|c|c|c|c||c|c|c|c|c|}
\hline \multicolumn{1}{|c||}{ matrix } & \multicolumn{6}{c|}{$\mathrm{Al}$} & \multicolumn{5}{|c|}{6061} \\
\hline temperature & $20^{\circ} \mathrm{C}$ & $100^{\circ} \mathrm{C}$ & $200^{\circ} \mathrm{C}$ & $300^{\circ} \mathrm{C}$ & $400^{\circ} \mathrm{C}$ & $500^{\circ} \mathrm{C}$ & $20^{\circ} \mathrm{C}$ & $100^{\circ} \mathrm{C}$ & $200^{\circ} \mathrm{C}$ & $300^{\circ} \mathrm{C}$ & $400^{\circ} \mathrm{C}$ \\
\hline 0 vol.\% CF & 136 & 118 & 90 & 60 & 41 & 35 & 343 & 320 & 204 & 60 & 36 \\
5 vol.\% CF & 146 & 130 & 110 & 85 & 61 & 38 & 325 & 304 & 220 & 63 & 45 \\
10 vol.\% CF & 153 & 150 & 128 & 101 & 69 & 41 & 318 & 309 & 230 & 102 & 59 \\
15 vol.\% CF & 166 & 155 & 132 & 106 & 79 & 46 & 288 & 277 & 215 & 116 & 81 \\
\hline
\end{tabular}

Since the degree of interfacial reaction in 6061-matrix composites extruded from loose mixtures is similar to that in Al-matrix ones, the interfacial bonding strength in these composites is approximately equal. It means that the substitution of $\mathrm{Al}$ by the age hardened $\mathrm{Al}$-alloy-matrix, which possesses high yield stress, cannot increase the load transferred from matrix into the fibers. As the age hardened 6061-alloy exhibits much higher strength than $\mathrm{Al}$, the fiber volume fraction of 0.15 does not exceed the minimal value needed for fiber strengthening at room temperature. Similar behavior can be expected at $100^{\circ} \mathrm{C}$, since the matrix 


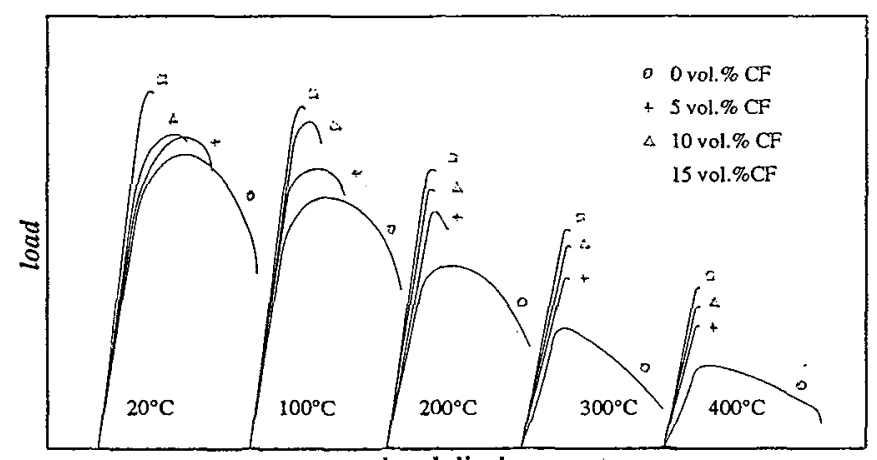

cross -head displacement

Fig. 6 Load-displacement curves recorded during tensile testing of Almatrix/CF composites at different temperatures fraction). This reduction can be attributed to the dislocation density gradient [9], residual stresses and to the residual porosity.

The weak fiber/matrix bonding in composites extruded from loose mixtures can be improved by controlled interfacial reaction. An annealing experiment was done with $\mathrm{Al}$-matrix/10 vol.\%CF composites extruded from loose mixture, in order to verify this assumption. The experiment was performed as follows; the composites were annealed at $600^{\circ} \mathrm{C}$ in air for different times, then furnace cooled and tensile tested. After tensile test the fragmented fibers were extracted from the fracture surface by dissolving the matrix in $\mathrm{HCl}$, and measured in order to determine the critical fiber length. Comparison of the fiber lengths after tensile test with initial lengths (before testing) has revealed that the fibers in unannealed or in for short time annealed composites were not fragmented during tensile testing. It confirms the assumption that the fibers had not attained their critical lengths. However, significant fragmentation of fibers was observed in composites annealed for longer time (Fig. 7) The fibers were fragmented into short lengths, between $l_{c} / 2$ and $l_{c}$. Critical fiber length $l_{c}$ was then obtained from the mean length of fragments $l_{m}\left(l_{c}=4 l_{m} / 3\right)$. The results are summarized in Table 3.

Table 3 UTS, elongation $A_{5}$, aluminum carbide amount $A l_{4} C_{3}$ and critical fiber aspect ratio $l_{c} d d$ in Al-matrix $/ 10$ vol.\% CF composites extruded from loose mixtures and annealed at $600^{\circ} \mathrm{C}$ for different time

extrusion temperature $-650^{\circ} \mathrm{C} ; l_{m} / d$ - fiber aspect ratio in composites after tensile test (initial lld -20 )

\begin{tabular}{|c||c|c|c|c|c|}
\hline annealing time [min] & UTS $[\mathrm{MPa}]$ & $A_{5}[\%]$ & $A l_{4} C_{3}[\mathrm{wt} . \%]$ & $l_{m} / d$ & $l_{d} d d$ \\
\hline \hline 0 & 152 & 12.5 & 0.110 & 21.0 & $>21.0$ \\
60 & 177 & 9.5 & 0.335 & 20.3 & $>20.3$ \\
120 & 171 & 11.3 & 0.465 & - & - \\
300 & 167 & 10.2 & 0.773 & 11.5 & 15.3 \\
600 & 167 & 13.1 & 1.051 & 8.5 & 11.3 \\
1140 & 168 & 13.3 & 1.171 & 6.3 & 8.4 \\
\hline
\end{tabular}

The critical fiber length decreases with increasing annealing time at $600^{\circ} \mathrm{C}$, due to improving of interfacial bonding strength. The strength of composite should then increase. However, this was not observed. Considerable reduction of fiber strength caused by interfacial reaction was probably the main reason for this discrepancy (reduction of fiber strength leads also to the reduction of critical fiber length). Masson et al.[10] have reported the strength of HM-35 carbon fibers coated with aluminum being $1762 \pm 352 \mathrm{MPa}$ after annealing at $650^{\circ} \mathrm{C}$ for $60 \mathrm{~min}$ (initial fiber strength was $4275 \pm 793 \mathrm{MPa}$ ). It means that the positive effect of fiber/matrix bonding improvement due to annealing has been diminished by reduction of the fiber strength, resulting in low tensile stress born in the fibers. Fiber strength is maximum in the first stage of annealing. However, insufficient bonding in this case leads to high critical length. This length could not be achieved by extrusion. The effect of increasing bonding strength, after annealing time up to $60 \mathrm{~min}$, exceeds the negative influence of fiber weakening at the same time, which results in slight strength 


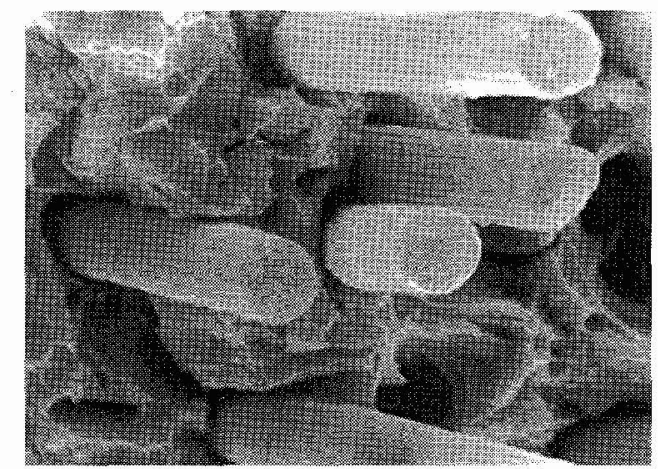

a.

$10 \mu \mathrm{m}$

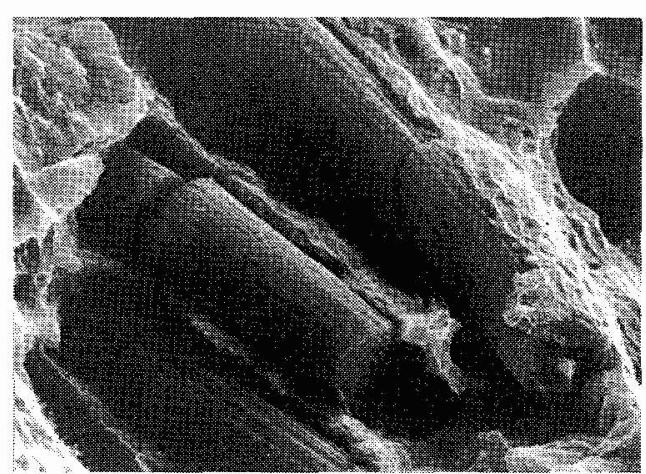

b.

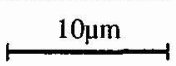

Fig. 7 Fracture surfaces of extruded Al-matrix/CF composites before (a) and after annealing at $600^{\circ} \mathrm{C} \mathrm{for} 10$ hours $(\mathrm{b})$

improvement. However, after this period significant fiber weakening takes place, the effect of fiber strengthening becomes less pronounced and the strength of the composite is controlled mostly by the matrix strength.

It should be noted that the interfacial shear stress $\tau$ is not constant along the fiber length. It is likely that the interfacial bonding strength in annealed composites is higher than average $\tau$. The fiber can be stressed up to its strength, then it will break with simultaneous reduction of the average axial tensile stress. During further loading the fiber debonding occurs, if the fiber length is shorter than critical one. The roughness of the debonded fiber surface increases with annealing time (Fig. 7), causing higher frictional stresses on the interface during further deformation and thus resulting in an increase of the fiber axial tensile stress. If this stress attains the fiber strength, the fiber fails again. Following this mechanism, the fiber can be continuously fragmented into short lengths if the matrix is able to withstand increasing stress after fiber fracture (e.g. if $V_{f}<V_{\min }$ ).

\section{ACKNOWLEDGMENTS}

We thank "AMAG-Forschung und Entwicklung GesmbH" for financial support and Dr.H.Danninger of Technical University Vienna for helpful discussions.

\section{REFERENCES}

[1] Katzman, H.A., Mater. Manufact. Proc, 5 (1990), 1, pp.1.

[2] Kainer, K.U. and Tertel, A., In: Proc. I2th Riso Int. Symp. on Mater. Sci., (N.Hansen et al. eds.), p.435. Riso National Laboratory, Roskilde (1991), Denmark.

[3] Kryze, J., Bréban, P., Baptiste, D. and François, D., In: Proc. 12th Riso Int. Symp. on Mater. Sci., (N.Hansen et al. eds.), p.455. Riso National Laboratory, Roskilde (1991)., Denmark.

[4] Simancik, F., Jangg, G., In: Proc. Int. Symp. on Composites: Fracture mech. and technology. (S.T. Mileiko and V.V. Tvardovsky eds.), p.233. Russian Composite Society, Chernogolovka (1992), Russia.

[5] Halpin, J.C., J. Comp. Mater. 3 (1969), p.732.

[6] Simancik, F., Dissertation. Technische Universität Wien, Technische Naturwissenschaftliche Fakultät (1993), Wien.

[7] Kelly, A. and Macmillan, N.H. (ed.), Strong solids. pp.284-287.Clarendon Press (1986)., Oxford.

[8] Arsenault, R.J., Wang, L. and Feng, C.R., Acta metall mater. 39 (1991), p.47.

[9] Masson, J.J., Schulte, K., Girot. F. and Le Petitcorps, Y., Mater, Sci. Eng. A135 (1991), pp.59.

[10] Dutta, I. and Bourell, D.L., Acta metall. mater. 38 (1990), p.2041. 